13

\title{
Теория термоэмиссионных и вторично-эмиссионных свойств палладий-бариевых катодов электровакуумных сверхвысокочастотных приборов
}

\author{
(C) В.И. Капустин, ${ }^{1,2}$ И.П. Ли, ${ }^{2}$ С.О. Москаленко, ${ }^{1,2}$ А.В. Шуманов ${ }^{1,2}$ \\ ${ }^{1}$ МИРЭА - Российский технологический университет, \\ 119454 Москва, Россия \\ ${ }^{2} \mathrm{AO}$ „Плутон“, \\ 105120 Москва, Россия \\ e-mail: kapustin@mirea.ru
}

Поступило в Редакцию 14 мая 2019 г.

В окончательной редакции 14 мая 2019 г.

Принято к публикации 5 июня 2019 г.

\begin{abstract}
Предложена модель структуры поверхности палладий-бариевого катода, и на основе модели вторичной электронной эмиссии Дайона проведен расчет зависимости коэффициента вторичной электронной эмиссии кристаллитов оксида бария, формирующихся на поверхности катода при его термическом активировании, от температуры и концентрации кислородных вакансий в оксиде. Показано, что эмиссионные свойства палладий-бариевого катода существенно зависят не только от эмиссионных свойств кристаллитов оксида бария, но и от относительной площади поверхности катода, занятой указанными кристаллитами. Построены теоретические номограммы, связывающие измеряемые усредненные по поверхности величины работы выхода и коэффициента вторичной электронной эмиссии палладий-бариевого катода, при этом параметрами номограмм являются температура, концентрация кислородных вакансий в кристаллитах оксида бария и относительная площадь поверхности катода, занятая кристаллитами оксида бария.
\end{abstract}

Ключевые слова: термоэлектронная эмиссия, вторичная электронная эмиссия, палладий-бариевый катод, оксид бария.

DOI: $10.21883 /$ JTF.2020.02.48829.195-19

\section{Введение}

Палладий-бариевые катоды нашли широкое применение в магнетронных усилителях и генераторах СВЧ диапазона длин волн, в том числе в безнакальных магнетронах с мгновенным временем готовности [1]. Схема катодного узла такого прибора показана на рис. 1, где 1 - анодный блок магнетрона, 2 - керн катода, 3 - подогреватель, 4 - концевые экраны, 5 - автоэмиссионные катоды в виде танталовых шайб толщиной $2-4 \mu \mathrm{m}$, выступающие над поверхностью катода на 100-200 $\mu \mathrm{m}, 6$ - палладий-бариевые катодные шайбы. В катодном узле такого типа подогреватель 3 используется только на этапе активирования катода прогревом в вакууме $10^{-7} \mathrm{~Pa}$ при температуре $1070^{\circ} \mathrm{C}$ в течение $6-8 \mathrm{~h}[1]$. Автоэлектронная эмиссия с торцевой поверхности шайб 5 происходит с так называемых вискеров, формирующихся на этапе активирования катода в виде палладиевых столбиков диаметром в доли микрона и высотой в несколько микрон, и обеспечивает запуск прибора в безнакальном режиме при подаче на катод импульсного напряжения величиной 4-8kV. Катод в приборах такого типа подвергается обратной электронной бомбардировке со средней мощностью 5-15 W/cm ${ }^{2}$, которая и обеспечивает разогрев катода до рабочей температуры, составляющей $300-700^{\circ} \mathrm{C}$.
Палладий-бариевые катоды получают прессованием композиции из порошка палладия и порошка интерметаллида $\mathrm{Pd}_{5} \mathrm{Ba}$ с содержанием интерметаллида в композиции 1.5-5.0\%. Интерметаллид $\mathrm{Pd}_{5} \mathrm{Ba}$ обычно получают электродуговой переплавкой бария и палладия в среде аргона с избытком палладия в количестве 5-8\% по отношению к стехиометрии соединения. При этом

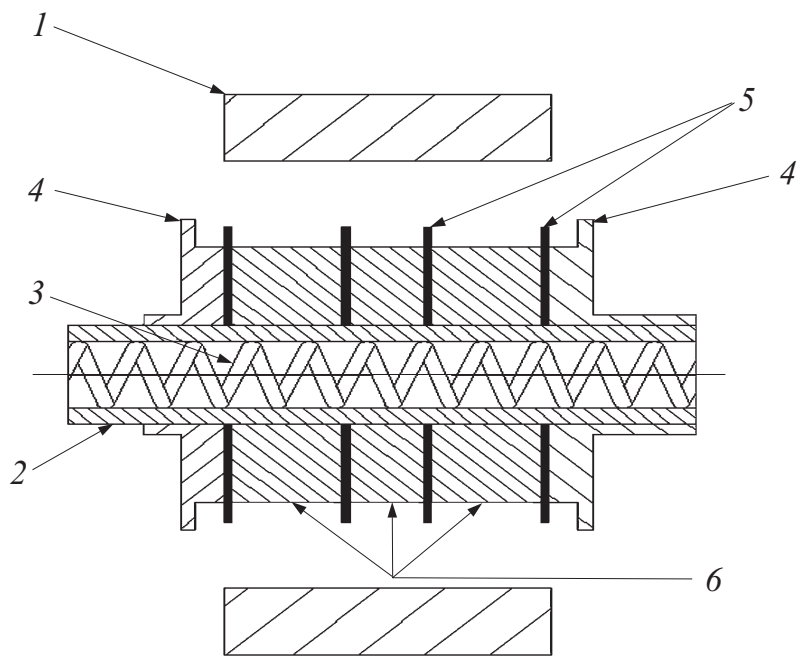

Pис. 1. Конструкция катодного узла магнетрона с безнакальным запуском. 
избыточный палладий после переплавки характеризуется повышенным содержанием кислорода по сравнению с исходным палладием.

В зависимости от технологии материала палладийбариевого катода и режима его активирования величина экспериментально измеряемого максимального коэффициента вторичной электронной эмиссии (КВЭЭ) $\sigma_{m}$ материала катода лежит в интервале 2.45-2.85, а величина экспериментально измеряемой работы выхода $\varphi-$ $2.3-2.7 \mathrm{eV}$ [2]. При этом величину КВЭЭ материала катода обычно измеряют при комнатной температуре или при температуре ниже рабочей температуры катода, при которой ток термоэмиссии не накладывается на ток вторичной электронной эмиссии, а величину работы выхода - при температуре $950-1100^{\circ} \mathrm{C}$. Поэтому температурные режимы измерения эмиссионных параметров катодных материалов не соответствуют режиму работы катода в СВЧ приборе. В то же время для СВЧ генераторов и усилителей от катодного материала требуется различное сочетание значений параметров $\sigma_{m}$ и $\varphi$ при различающейся рабочей температуре катодов.

Целью настоящей работы является разработка теории палладий-бариевых катодных материалов, описывающей соотношение между истинными значениями параметров $\sigma_{m}$ и $\varphi$ материалов в зависимости от температуры и степени активирования катодов.

\section{Модель структуры поверхности палладий-бариевого катода}

В литературе до последнего времени распространенными являлись представления о „пленочном“ механизме работы $\mathrm{Pd}-\mathrm{Ba}$ катода [3,4], согласно которым на поверхности такого катода формируется моноатомная пленка бария, которая снижает потенциальный барьер на поверхности катодного материала, снижая тем самым величину $\varphi$ и увеличивая величину $\sigma_{m}$. Однако в работе [5] с использованием методов прецизионного рентгеноструктурного анализа, оптической спектроскопии, электронной спектроскопии для химического анализа и спектроскопии характеристических потерь энергии электронов было экспериментально показано, что при активировании палладий-бариевого катода на его поверхности формируются два типа нанокристаллитов оксида бария, определяющих эмиссионные свойства такого катодного материала, первый из которых нанокристаллиты $\mathrm{BaO}_{(1-x)}$, второй - нанокристаллиты $\mathrm{Ba}_{1-y} \mathrm{O}_{1-x} \mathrm{Pd}_{y}$. Формирование таких кристаллитов идет по реакциям

$$
\begin{gathered}
\mathrm{O}[\mathrm{Pd}]+\mathrm{Pd}_{5} \mathrm{Ba}=\mathrm{BaO}_{(1-x)}, \\
\mathrm{O}[\mathrm{Pd}]+\mathrm{Pd}_{5} \mathrm{Ba} \Rightarrow \mathrm{Ba}_{(1-y)} \mathrm{O}_{(1-x)} \mathrm{Pd}_{y},
\end{gathered}
$$

где $\mathrm{O}[\mathrm{Pd}]$ - кислород, растворенный в кристаллитах палладия после его переплавки, $x$ - отклонение от стехиометрии кристаллитов $\mathrm{BaO}$ за счет формирования

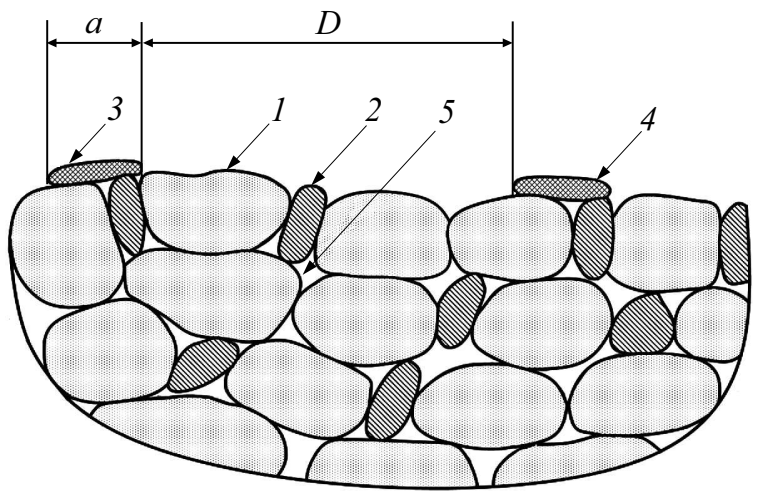

Рис. 2. Структура поверхности палладий-бариевого катода.

в них кислородных вакансий, $y$ - отклонение от стехиометрии $\mathrm{BaO}$ за счет растворенных в кристаллитах оксида бария микропримесей палладия. При этом в кристаллитах первого и второго типа кислородные вакансии определяют их эмиссионные свойства, а в кристаллитах второго типа микропримеси палладия дополнительно упорядочивают пространственное распределение кислородных вакансий. По данным работы [5] объемная $N_{D}$ и поверхностная $N_{S}$ концентрации кислородных вакансий в кристаллитах первого и второго типа практически совпадают и лежат в интервалах $N_{D}=1.8-1.9 \cdot 10^{25} \mathrm{~m}^{-3}$, $N_{S}=1.6-1.7 \cdot 10^{25} \mathrm{~m}^{-3}$.

На основании этих экспериментальных результатов на рис. 2 приведена модель структуры поверхности палладий-бариевого катода. На рисунке обозначено: 1 частицы порошка палладия, 2 - частицы порошка интерметаллида $\mathrm{Pd}_{5} \mathrm{Ba}, 3$ и 4 - нанокристаллиты $\mathrm{BaO}$ первого и второго типа, 5 - поры катодного материала, а $a$ - характерный размер нанокристаллитов, $D$ характерное расстояние между нанокристаллитами.

В соответствии с физикохимией эмиссионных свойств сплавов [6] величина максимального КВЭЭ интерметаллида $\mathrm{Pd}_{5} \mathrm{Ba}$ должна лежать в интервале $\sigma_{m}=1.55-1.65$, так как для бария и палладия эти значения составляют $\sigma_{m}(\mathrm{Ba})=0.9$ и $\sigma_{m}(\mathrm{Pd})=1.70$. Так как площадь катода, занятая кристаллитами интерметаллида, мала, а его КВЭЭ мало отличается от КВЭЭ палладия, то КВЭЭ палладий-бариевого катода определяется величиной КВЭЭ палладия и кристаллитов оксида бария, сформировавшихся в процессе активирования катода, и приближенно равен

$$
\sigma_{m}=\left[1-\frac{a^{2}}{(a+D)^{2}}\right] \sigma_{m}(\mathrm{Pd})+\left[\frac{a^{2}}{(a+D)^{2}}\right] \sigma_{m}(\mathrm{BaO}) .
$$

Величина работы выхода палладия равна $4.8 \mathrm{eV}$, при этом величина работы выхода бария составляет $2.5 \mathrm{eV}$. В соответствии с физикохимией эмиссионных свойств сплавов [6] величина работы выхода интерметаллида $\mathrm{Pd}_{5} \mathrm{Ba}$ должна лежать в интервале $4.5-4.6 \mathrm{eV}$. Поэтому измеряемая величина работы выхода $\varphi$ палладий- 
бариевого катода, которая рассчитывается по вольтамперным характеристикам и с использованием уравнения Ричардсона без учета „пятнистости“ поверхности катода, будет определяться работой выхода кристаллитов оксида бария и может быть представлена соотношением

$$
\varphi=\varphi_{0}+k T \ln \left[\frac{(a+D)^{2}}{a^{2}}\right],
$$

где $\varphi_{0}$ - истинное значение работы выхода кристаллитов оксида бария.

Таким образом, значения эмиссионных параметров $\sigma_{m}$ и $\varphi$ палладий-бариевого катода будут определяться температурой катода, а также параметрами $a, D$ и $x$, т.е. величиной относительной площади поверхности катода, занятой кристаллитами оксида бария, и концентрацией кислородных вакансий в кристаллитах оксида бария.

Если относительная площадь поверхности катода, занятая кристаллитами оксида бария, составляет 5-8\% от площади катода, то с учетом соотношений (3) и (4) можно оценить, что измеряемая величина максимального КВЭЭ кристаллитов оксида бария должна лежать в интервале $\sigma_{m}=8-14$, при этом величина измеряемой работы выхода $\varphi_{0}$ выше истинного значения $\varphi_{0}$ на $0.2-0.3 \mathrm{eV}$, которое при температуре $1000 \mathrm{~K}$ должно лежать в интервале $2.0-2.4 \mathrm{eV}$.

\section{Теория вторично-эмиссионных свойств оксида}

Величину максимального КВЭЭ оксида $\sigma_{m}$ в соответствии с известной моделью Дайона $[7,8]$ можно представить в виде

$$
\sigma_{m}=\frac{B}{\xi}\left(\frac{C \rho n}{\alpha}\right)(\alpha l)^{(1-n)}\left(1-e^{-\alpha l}\right),
$$

где $B-$ вероятность выхода вторичных электронов в вакуум, $\xi$ - средняя энергия возбужденных вторичных электронов, обеспечивающая его выход в вакуум, $l-$ глубина проникновения первичных электронов в твердое тело, $\lambda=1 / \alpha$ - длина свободного пробега вторичных электронов до их выхода в вакуум, $\rho-$ плотность вещества, $C$ - постоянная Виддингтона, $n=1.35-$ константа, входящая в выражение для потерь энергии первичными электронами при их торможении в твердом теле

$$
\frac{d E}{d x}=-\frac{C \rho}{E^{(n-1)}} .
$$

Так как КВЭЭ достигает своего максимального значения при $\lambda \cong l$, то из (5) и с учетом выражения для глубины $(l)$ проникновения первичных электронов с энергией $E_{p}[7]$

$$
l=\frac{E_{p}^{n}}{n C \rho}
$$

следуют выражения для величины максимального КВЭЭ материала и энергии первичных электронов $E_{p m}$, при которой достигается максимальный КВЭЭ

$$
\sigma_{m}=\frac{B}{\xi}\left(\frac{C \rho}{\alpha}\right)^{1 / n}, \quad E_{p m}=\left(\frac{C \rho}{\alpha}\right)^{1 / n} .
$$

В выражении (5) величина $B$ будет зависеть от температуры и концентрации кислородных вакансий, а величины $\xi$ и $\alpha-$ от указанных параметров, а также от характера зонной структуры оксида, прежде всего от ширины запрещенной зоны оксида и электронной концентрации в валентной зоне.

Вторичные электроны в оксидах образуются прежде всего при возбуждении первичными электронами электронов валентной зоны. Поэтому в первом приближении для оксидов, являющихся диэлектриками с широкой запрещенной зоной, величина $\xi$ при отсутствии в оксиде кислородных вакансий приближенно имеет вид

$$
\xi=E_{g}+\chi
$$

а при наличии в нем кислородных вакансий - вид

$$
\xi=E_{g}+\chi+V
$$

где $E_{g}-$ ширина запрещенной зоны оксида, $\chi-$ величина электронного сродства оксида, $V$ - величина искривления энергетических зон вблизи поверхности оксида.

Энергетическое распределение возбужденных вторичных электронов в твердом теле в первом приближении подчиняется обратному степенному закону $S(E) \propto E^{-m}$, при этом $m \cong 2$ [9]. Так как вероятность выхода вторичных электронов пропорциональна интегралу от $S(E)$ для интервала энергий выше потенциального барьера на границе твердого тела, то приближенно можно положить

$$
B \sim \frac{1}{(\chi+V)}
$$

Длина свободного пробега вторичных электронов $\lambda$ до их выхода в вакуум может быть представлена выражением

$$
\frac{1}{\lambda}=\frac{1}{\lambda_{0}}+\frac{1}{\lambda_{T}}+\frac{1}{\lambda_{D}},
$$

где $\lambda_{0}$ - длина свободного пробега относительно рассеяния на электронах оксида, прежде всего на электронах валентной зоны, $\lambda_{T}$ - длина свободного пробега относительно рассеяния на фононах, $\lambda_{D}$ - длина свободного пробега относительно рассеяния на ионизированных кислородных вакансиях.

С учетом вышеизложенного в общем случае величину максимального КВЭЭ оксида можно представить в виде

$$
\sigma_{m}=A \frac{1}{(\chi+V)} \frac{1}{\left(E_{g}+\chi+V\right)} \frac{1}{\left(\frac{1}{\lambda_{0}}+\frac{1}{\lambda_{T}}+\frac{1}{\lambda_{D}}\right)^{0.74}},
$$

где $A-$ константа, в соответствии с (8) зависящая от плотности вещества $A \propto(\rho)^{0.74}$. 
В соответствии с $[10]$ величину $\lambda_{T}$ для оксидов можно записать в виде

$$
\lambda_{T}=\frac{\beta}{\left(2 n_{v}+1\right)^{1 / 2}},
$$

где величина $n_{v}$ и температура Дебая $T_{\mathrm{D}}$ равны

$$
n_{v}=\exp \left(\frac{h v}{k T}\right)-1, \quad \frac{h v}{k}=T_{D}
$$

В соответствии с [11] величину $\lambda_{D}$ можно представить в виде

$$
\lambda_{D}=\frac{4}{\pi N_{D+}^{1 / 3}},
$$

где $N_{D+}$ - концентрация термически ионизированных вакансий, равная

$$
N_{D+}=\sqrt{\frac{N_{C} N_{D}}{2}} \cdot \exp \left(-\frac{\Delta E_{g}}{2 k T}\right), \quad N_{C}=2 \cdot\left(\frac{m k T}{2 \pi \hbar^{2}}\right)^{3 / 2},
$$

где $\Delta E_{g}-$ „глубина“ донорного уровня кислородных вакансий относительно дна зоны проводимости, равная для оксида бария $1.8 \mathrm{eV}$.

Величина искривления энергетических зон у поверхности оксида, обусловленная локализованным на поверхности оксида зарядом поверхностных кислородных вакансий, в соответствии с [11] может быть определена из уравнения

$$
\begin{aligned}
& 2 \varepsilon \varepsilon_{0} k T \sqrt{\frac{N_{C} N_{D}}{2}} \exp \left(-\frac{\Delta E_{g}}{2 k T}\right)\left[\exp \left(\frac{v}{k T}\right)\right. \\
& \left.+\exp \left(-\frac{v}{k T}\right)-2\right]=\left[\frac{e N_{S}}{1+\sqrt{\frac{2 N_{C}}{N_{D}} \exp \left(-\frac{\Delta E_{g}-2 V}{k T}\right)}}\right]^{2},
\end{aligned}
$$

где $N_{D}-$ концентрация кислородных вакансий в объеме оксида, $N_{S}$ - концентрация вакансий на поверхности оксида, $\varepsilon$ - диэлектрическая проницаемость оксида, $\varepsilon_{0}-$ диэлектрическая постоянная, $V-$ величина искривления энергетических зон у поверхности, $k-$ постоянная Больцмана, $T$ - температура, $m-$ масса электрона, $\hbar-$ постоянная Планка. При этом объемная $N_{D}$ и поверхностная $N_{S}$ концентрации вакансий связаны соотношением, полученным с использованием методов теории абсолютных скоростей реакций [11]

$$
N_{S}=N_{S O} \exp \left(-\frac{E_{4}-E_{1}}{k T}\right)+d N_{D} \exp \left(-\frac{E_{2}-E_{1}}{k T}\right),
$$

где $N_{\text {SO }}-$ поверхностная плотность атомов в оксиде, $d$ - параметр кристаллической решетки оксида, $E_{1}$ - энергия активации перехода атома кислорода из второго монослоя в вакансию в первом монослое, $E_{2}-$ энергия активации перехода атома кислорода из первого монослоя в вакансию во втором монослое, $E_{4}-$ энергия активации перехода атома кислорода из первого монослоя в адсорбированное состояние на поверхности оксида.

\section{Расчет КВЭЭ оксида бария}

Для определения зависимости КВЭЭ оксида бария от температуры и концентрации кислородных вакансий необходимы значения параметров $\beta, \lambda_{0}$ и нормировочного множителя $A$, входящих в выражение (13). Так как данные параметры для оксида бария экспериментально не определены, их можно найти из сопоставления электронной структуры оксида бария и оксида магния с учетом известных зависимостей КВЭЭ $\mathrm{MgO}$ от температуры, зависимости длины свободного пробега электронов в $\mathrm{MgO}$ от энергии, зависимости КВЭЭ от ширины запрещенной зоны ионных кристаллов [10].

Действительно, $\mathrm{MgO}$ характеризуется плотной кристаллической структурой, в которой затруднено формирование точечных дефектов [12], поэтому для оксида магния для величины искривления энергетических зон можно положить $V(300 \mathrm{~K})=V(1000 \mathrm{~K})=0$ и величиной $\lambda_{D}$ в соотношении (12) можно пренебречь, если в $\mathrm{MgO}$ специально не созданы дефекты точечного типа, например кислородные вакансии.

Валентные зоны $\mathrm{MgO}$ и $\mathrm{BaO}$ одинаковы - на них, соответственно на $L$-оболочке и $O$-оболочке, находятся по 8 электронов. То есть параметры $\lambda_{0}$ в первом приближении для $\mathrm{MgO}$ и $\mathrm{BaO}$ можно принять равными. Кристаллические структуры $\mathrm{MgO}$ и $\mathrm{BaO}$ - кубические типа $\mathrm{NaCl}$, но с различающимися параметрами кристаллической решетки [12]. Значения температуры Дебая в соответствии с [13] для оксида магния равна $T_{\mathrm{D}}(\mathrm{MgO})=400 \mathrm{~K}$, для оксида бария $T_{D}(\mathrm{BaO})=300 \mathrm{~K}$. Ширина запрещенной зоны в $\mathrm{MgO}$ равна $E_{g}=7.8 \mathrm{eV}[12]$, в $\mathrm{BaO}$ по нашим измерениям $E_{g}=4.7 \mathrm{eV}[14]$.

Для $\mathrm{MgO}$ при температуре $25^{\circ} \mathrm{C}(\approx 300 \mathrm{~K})$ величина $\sigma_{m}=7.2$, а при температуре $740^{\circ} \mathrm{C}$ величина $\sigma_{m}=6.3[10]$. При этом в $\mathrm{MgO}$ при температуре $300 \mathrm{~K}$ и энергии первичных электронов $E_{p}=E_{p m}$ длина свободного пробега электронов $\lambda=300 \AA$. Величина электронного сродства магния и бария одинакова, поэтому

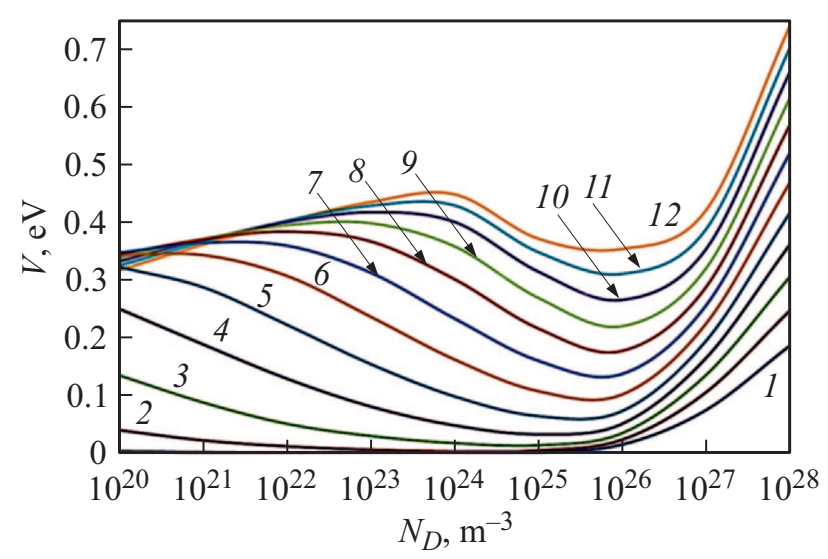

Рис. 3. Зависимость величины искривления энергетических зон $\mathrm{BaO}$ от концентрации кислородных вакансий при различных значениях температуры. 


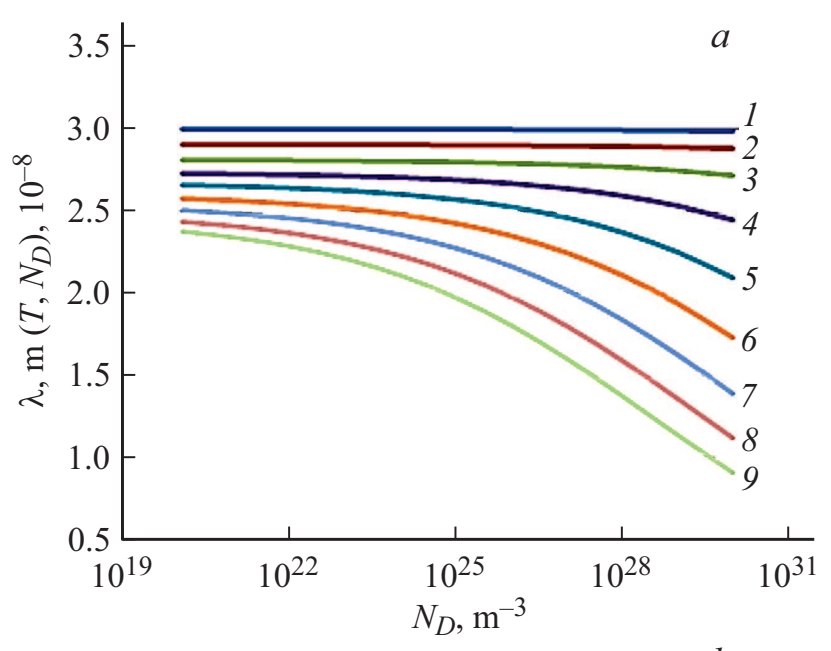

$b$

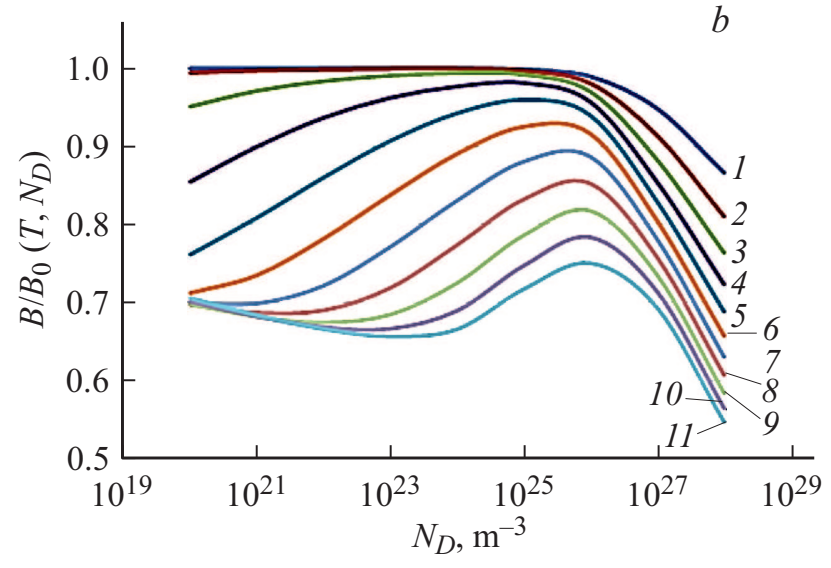

Рис. 4. Зависимости длины свободного пробега электронов $(a)$ и относительной вероятности выхода вторичных электронов $(b)$ из $\mathrm{BaO}$ от концентрации кислородных вакансий при различных значениях температуры.

для их оксидов - $\mathrm{MgO}$ и $\mathrm{BaO}-$ можно положить $\chi=0.8 \mathrm{eV}[12,14]$. С учетом приведенных выше параметров вторичной электронной эмиссии $\mathrm{MgO}$ и на основании соотношений (12), (14) и (15), расчет дает для оксида магния значения параметров $\beta=1.43 \cdot 10^{-7} \mathrm{~m}$, $\lambda_{0}=4.14 \cdot 10^{-8} \mathrm{~m}$, которые и могут быть использованы для $\mathrm{BaO}$.

На рис. 3 приведены расчетные зависимости величины искривления энергетических зон $\mathrm{BaO}$ от концентрации кислородных вакансий, выполненные с использованием уравнения (18) по методике, предложенной в [15]. Кривые на рис. 3 соответствуют следующим значениям температуры: 1 - 400, 2-500, 3-600, 4 - 700, 5 $800,6-900,7-1000,8-1100,9-1200,10-$ $1300,11-1400,12-1500 \mathrm{~K}$.

На рис. 4, а приведены результаты расчета длины свободного пробега электронов в $\mathrm{BaO}$ в соответствии с выражением (12), а на рис. $4, b$ - вероятности выхода вторичных электронов в соответствии с (11) относительно вероятности выхода при температуре $T=300 \mathrm{~K}$ и концентрации вакансий $N_{D}=10^{21} \mathrm{~m}^{-3}$, которая пример- но соответствует равновесной концентрации дефектов Шоттки по кислородным вакансиям, всегда присутствующих в оксиде. На рис. 4, $a$ расчетные кривые соответствуют температуре: $1-300,2-400,3-500,4-$ $600,5-700,6-800,7-900,8-1000,9-$ $1100 \mathrm{~K}$. На рис. 4, $b$ расчетные кривые соответствуют температуре: $1-300,2-400,3-500,4-600$, $5-700,6-800,7-900,8-1000,9-1100,10-$ $1200,11-1300 \mathrm{~K}$.

При нахождении нормировочного параметра $A$, необходимого для определения зависимости абсолютного значения КВЭЭ оксида бария от температуры и концентрации кислородных вакансий, были учтены приведенные выше параметры вторичной электронной эмиссии $\mathrm{MgO}$ и соотношение параметра $A(\mathrm{BaO})$ для оксида бария и $A(\mathrm{MgO})$ для оксида магния, зависящих от физической плотности оксидов $\rho(\mathrm{MgO})$ и $\rho(\mathrm{BaO})$

$$
A(\mathrm{BaO})=A(\mathrm{MgO}) \cdot[\rho(\mathrm{BaO}) / \rho(\mathrm{MgO})]^{0.74} .
$$

На рис. 5 приведены расчетные зависимости величины КВЭЭ оксида бария от концентрации кислородных вакансий. Кривые соответствуют следующим значениям температуры: 1 - 300, 2 - 400, 3 - 500, 4 - 600, 5 $700,6-800,7-900,8-1000,9-1100 \mathrm{~K}$.

Кристаллиты оксида бария, формирующиеся в палладий-бариевом катоде, должны обладать определенным сочетанием параметров $\sigma_{m}$ и истинного значения величины работы выхода $\varphi_{0}$. На рис. 6 приведены расчетные номограммы соотношения между истинной работой выхода оксида бария $\varphi_{0}$ и величиной максимального КВЭЭ $\sigma_{m}$ при фиксированных значениях температуры, но при изменении в оксиде бария концентрации кислородных вакансий. На рис. 6 расчетные кривые соответствуют температуре: $1-300,2-400,3-500$, $4-600,5-700,6-800,7-900,8-1000,9-$ $1100 \mathrm{~K}$. Расчетной точке $A$ (правые окончания кривых) на каждой кривой соответствует концентрация вакансий $1 \cdot 10^{20} \mathrm{~m}^{-3}$, расчетной точке $B$ (левые нижние окончания кривых) - концентрация вакансий $1 \cdot 10^{28} \mathrm{~m}^{-3}$, при этом расчетные точки на кривых отстоят на порядок величины концентрации вакансий.

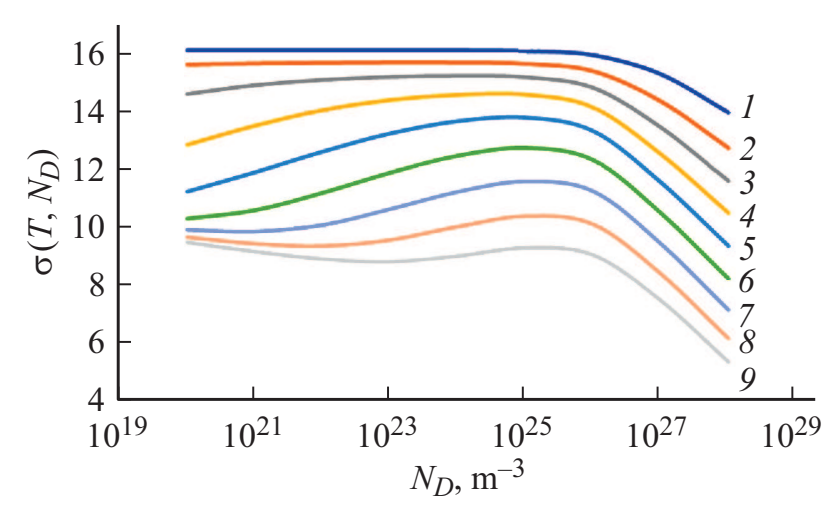

Рис. 5. Зависимости КВЭЭ $\mathrm{BaO}$ от концентрации кислородных вакансий при различных значениях температуры. 


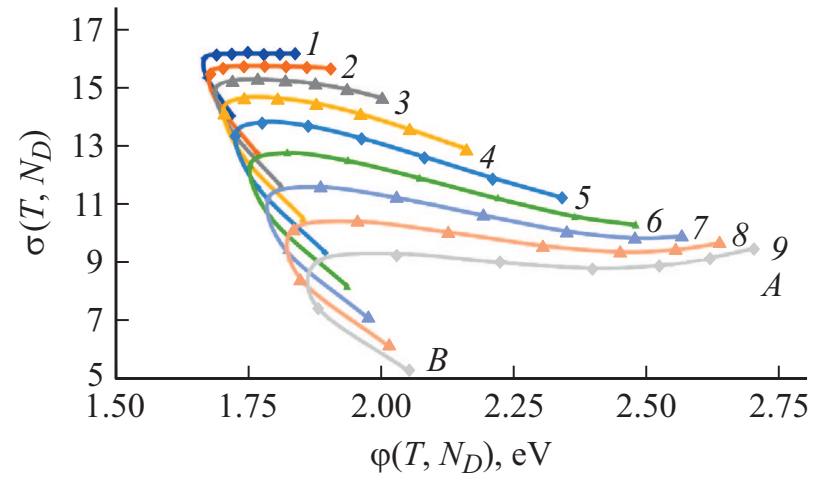

Рис. 6. Номограммы соотношений КВЭЭ $\sigma_{m}$ и истинной работы выхода $\varphi_{0} \mathrm{BaO}$ от концентрации кислородных вакансий при различных значениях температуры.

Как видно на рис. 6, в зависимости от температуры и концентрации кислородных вакансий соотношение работы выхода и максимального КВЭЭ оксида бария меняется сложным образом. В интервале температур $600-900 \mathrm{~K}$ с ростом концентрации кислородных вакансий работа выхода оксида бария значительно уменьшается, при этим имеет место и рост величины КВЭЭ. При температуре ниже 600 К и выше 900 К при уменьшении работы выхода величина КВЭЭ меняется незначительно. При высокой концентрации кислородных вакансий во всем интервале температур с ростом концентрации вакансий работа выхода изменяется незначительно, при этом сильно уменьшается величина КВЭЭ.

\section{Эмиссионные свойства палладий-бариевого катода}

В соответствии с выражениями (3) и (4) измеряемые значения КВЭЭ $\sigma_{m}$ и работы выхода $\varphi_{0}$ палладийбариевого катода сильно зависят от относительной площади поверхности катода, занятой кристаллитами оксида бария, формирующимися в соответствии с реакциями (1) и (2). На рис. 7 приведены расчетные номограммы соотношения между измеряемой работой выхода оксида бария $\varphi$ и величиной максимального КВЭЭ $\sigma_{m}$ при фиксированных значениях температуры, но при изменении в оксиде бария концентрации кислородных вакансий, при условии, что кристаллиты оксида бария занимают $10 \%$ площади поверхности катода, а на рис. 8 - номограммы при условии, что кристаллиты оксида бария занимают $5 \%$ площади поверхности катода. На рис. 7 и 8 расчетные кривые соответствуют температуре: $1-300,2-$ $400,3-500,4-600,5-700,6-800,7-900$, $8-1000,9-1100 \mathrm{~K}$. Расчетной точке $C$ (правые окончания кривых) на каждой кривой соответствует концентрация вакансий $1 \cdot 10^{20} \mathrm{~m}^{-3}$, расчетной точке $D$ (левые нижние окончания кривых) - концентрация вакансий $1 \cdot 10^{28} \mathrm{~m}^{-3}$, при этом расчетные точки на кривых отстоят на порядок величины концентрации вакансий.
Анализ результатов, приведенных на рис. 7 и 8 , показывает, что, во-первых, рассчитанные значения эмиссионных параметров палладий-бариевого катода лежат в интервале их экспериментальных значений и, во-вторых, эти значения сильно зависят от температуры, а также от концентрации кислородных вакансий в кристаллитах оксида бария и от относительной площади поверхности катода, занятой этими кристаллитами, т. е. от технологии изготовления и активирования катода и его рабочей температуры. При этом параметры $a$ и $D$, входящие в соотношения (3) и (4), и значения которых могут быть оптимизированы на этапе разработки технологии катода, могут быт экспериментально определены с использованием методики, предложенной в работе [16] и основанной на детальном анализе вольт-амперных характеристик материала при измерении параметров термоэмиссии.

Так как палладий-бариевые катоды в электровакуумных магнетронных усилителях и генераторах работают в условиях импульсной обратной электронной бомбарди-

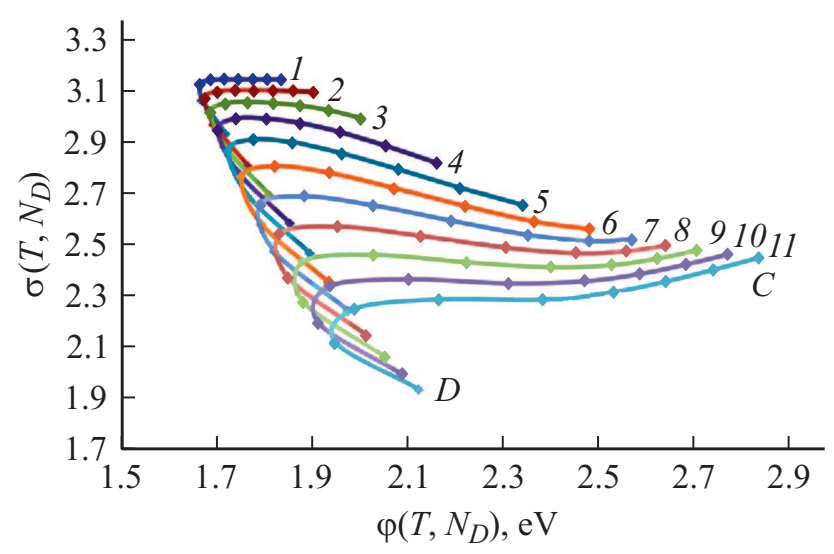

Рис. 7. Номограммы соотношений КВЭЭ $\sigma_{m}$ и измеряемой работы выхода $\varphi$ палладий-бариевого катода от концентрации кислородных вакансий в $\mathrm{BaO}$ при различных значениях температуры при площади поверхности $\mathrm{BaO}$, равной $10 \%$.

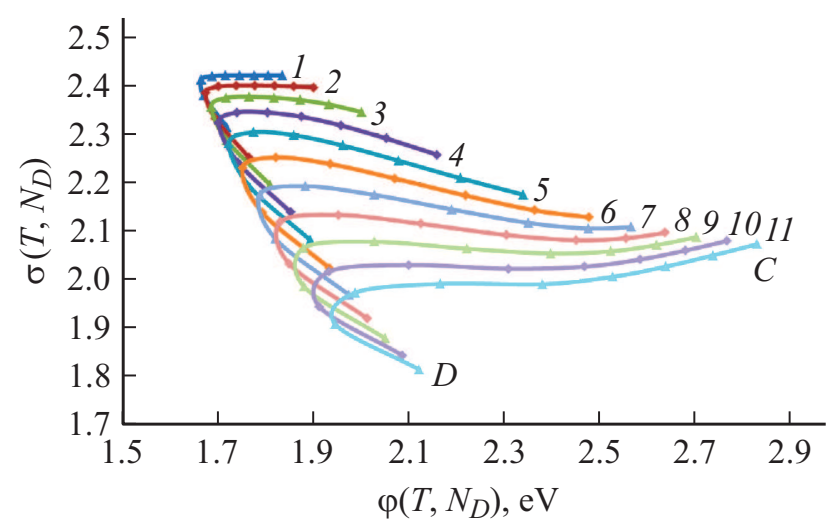

Рис. 8. Номограммы соотношений КВЭЭ $\sigma_{m}$ и измеряемой работы выхода $\varphi$ палладий-бариевого катода от концентрации кислородных вакансий в $\mathrm{BaO}$ при различных значениях температуры при площади поверхности $\mathrm{BaO}$, равной $5 \%$. 
ровки поверхности катода (до $15 \mathrm{~W} / \mathrm{cm}^{2}$ ) и при наличии у поверхности катода импульсной напряженности электрического поля (до $10 \mathrm{kV} / \mathrm{mm}$ ), то указанные факторы могут приводить к изменению величины КВЭЭ и работы выхода материала катода, сформированных на этапе его активирования, в результате действия двух физических факторов.

Во-первых, под действием обратной электронной бомбардировки может существенно измениться скорость испарения атомов кислорода и атомов бария из кристаллитов оксида бария, что приведет к изменению концентрации кислородных вакансий и соответственно изменению эмиссионных свойств кристаллитов оксида бария. Действительно, оксид бария, содержащий кислородные вакансии, является полупроводником $n$-типа, поэтому для концентрации электронов $\mathrm{n}$ и дырок $p$ выполняется соотношение $n \gg p$. При электронной бомбардировке поверхности оксида в нем генерируются электроннодырочные пары с концентрацией $\Delta n=\Delta p \gg p$, при этом величины $\Delta n$ и $\Delta p$ зависят от плотности тока и энергии электронов, бомбардирующих поверхность, дрейфовой подвижности электронов и дырок, скорости их рекомбинации, температуры и ряда других параметров. Так как испарение атомов кислорода и атомов бария из $\mathrm{BaO}$ протекает по квазихимическим реакциям

$$
\begin{gathered}
\mathrm{O}^{-s}+s \cdot(\Delta P) \leftrightarrow \mathrm{O}^{*} \rightarrow \mathrm{O} \uparrow, \\
\mathrm{Ba}^{+s}+s \cdot n \leftrightarrow \mathrm{Ba}^{*} \rightarrow \mathrm{Ba} \uparrow,
\end{gathered}
$$

где $\mathrm{O}^{*}$ и $\mathrm{Ba}^{*}$ - нейтральные атомы кислорода и бария на поверхности оксида, $s-$ эффективный заряд ионов в оксиде бария, равный $s=1.6 \mathrm{e}$, то из (21) следует, что под действием электронной бомбардировки скорость испарения атомов кислорода из оксида по сравнению со скоростью термического испарения существенно возрастет, в то время как скорость испарения атомов бария практически не изменится. То есть данное физическое явление сопровождается ростом концентрации кислородных вакансий у поверхности кристаллитов оксида бария. Детально теория неконгруэнтного испарения компонентов оксидов под действием электронной бомбардировки дана в работе [17].

Во-вторых, под действием электрического поля у поверхности оксида, которое проникает в полупроводник $n$-типа, имеет место дрейф и диффузия кислородных вакансий, что будет сопровождаться уменьшением концентрации кислородных вакансий у поверхности оксида. Кинетика изменения концентрации вакансий будет определяться толщиной кристаллитов оксида бария, температурой, коэффициентом диффузии и дрейфовой подвижностью атомов кислорода по кислородным вакансиям. Детально теория данного физического явления и методика экспериментального измерения толщины кристаллитов оксида бария и параметров диффузии и дрейфовой подвижности кислородных вакансий в оксиде дана в работе [18].
В целом влияние процессов неконгруэнтного термического испарения компонентов оксида бария, испарения компонентов под действием электронной бомбардировки и электрического поля, процессов межфазного взаимодействия в материале катода, взаимодействия материала катода с остаточной газовой средой СВЧ прибора на его эмиссионные свойства может быть учтено на основе кинетического подхода и с использованием кинетического уравнения, предложенных в работе [11].

\section{Заключение}

1.Вторично-эмиссионные и термоэмиссионные свойства палладий-бариевых катодных материалов в основном определяются кристаллитами оксида бария, содержащими кислородные вакансии, которые формируются на поверхности материала в процессе активирования катода прогревом в вакууме. При этом расчетные значения величины максимального КВЭЭ и величины работы выхода кристаллитов оксида бария в зависимости от температуры и концентрации кислородных вакансий в оксиде бария лежат в интервале $\sigma_{m}=5-16, \varphi=1.65-2.75 \mathrm{eV}$.

2.Измеряемые эмиссионные параметры палладийбариевого катода в электровакуумном СВЧ приборе магнетронного типа будут определяться их значениями для кристаллитов оксида бария, сформированными на этапе активирования катода, а также величиной относительной площади поверхности катода, занятой кристаллитами оксида бария, и могут лежать в интервале $\sigma_{m}=1.8-3.1$, $\varphi=1.7-2.9 \mathrm{eV}$.

3. В процессе работы импульсного СВЧ прибора магнетронного типа с палладий-бариевым катодом эмиссионные параметры такого катода могут существенно изменяться в результате действия нескольких факторов, основными из которых являются обратная электронная бомбардировка поверхности катода и электрическое поле у поверхности катода, при этом в зависимости от соотношения мощности электронной бомбардировки, величины электрического поля и температуры, величины КВЭЭ и работы выхода могут как уменьшаться, так и увеличиваться, при этом не синхронно.

\section{Конфликт интересов}

Авторы заявляют, что у них нет конфликта интересов.

\section{Список литературы}

[1] Ли И.П. // Электроника. Наука. Технологии. Бизнес. 2018. № 5. С. 144-151.

[2] Коржавый А.П. // Электронная промышленность. 1986. Вып. 3(151). С. 48-49.

[3] Дюбуа Б.Ч., Поливникова О.В. // Электронная техника. Сер. 1. СВЧ-техника. 2013. Вып. 4(519). С. 187-190.

[4] Дюбуа Б.Ч., Королев А.Н. // Электронная техника. Сер. 1. СВЧ-техника. 2011. Вып. 1(509). С. 5-25. 
[5] Капустин В.И., Ли И.П., Шуманов А.В., Москаленко С.O. // ЖТФ. 2019. Т. 89. Вып. 5. С. 771-780. [Kapustin V.I., Li I.P., Shumanov A.V., Moskalenko S.O. // Tech. Phys. 2019. Vol. 64. N 5. P. 460-466.]

[6] Савицкий Е.М., Буров И.В., Пирогова С.В., Литвак Л.Н. Электрические и эмиссионные свойства сплавов. М.: Наука, 1978. 294 с.

[7] Dionne G. // J. Appl. Phys. 1973. Vol. 44. P. 5361-5365.

[8] Dionne G. // J. Appl. Phys. 1975. Vol. 46. P. 3347-3351.

[9] Koshikawa T., Shimizi R.J. // J. Phys. D.: Appl. Phys. 1974. N 7. P. 1303-1315.

[10] Бронштейн И.М., Фрайман Б.С. Вторичная электронная эмиссия. М.: Наука, 1969. 408 с.

[11] Капустин В.И. // Перспективные материалы. 2000. № 2. C. 5-17.

[12] Лазарев В.Б., Соболев В.В., Шаплыгин И.С. Химические и физические свойства простых оксидов металлов. М.: Наука, 1983. 240 c.

[13] Абрамов М.А., Аляев В.А. // Вестник технологического университета. 2015. Т. 18. № 10. С. 50-51.

[14] Капустин В.И., Ли И.П., Шуманов А.В., Лебединский Ю.Ю., Заблочкий А.В. // ЖТФ. 2017. Т. 87. Вып. 1. C. 105-115. [Kapustin V.I., Li I.P., Shumanov A.V., Lebedinskii Yu.Yu., Zablotskii A.V.// Tech. Phys. 2017. Vol. 62. N 1. P. 116-126.]

[15] Капустин В.И. // Изв. АН СССР. Сер. Физ. 1991. Т. 55. № 12. C. $2455-2458$.

[16] Капустин В.И., Ли И.П., Шуманов А.В. // ЖТФ. 2018. T. 88. Вып. 3. С. 472-478. [Kapustin V.I., Li I.P., Shumanov A.V. // Tech. Phys. 2018. Vol. 63. N 3. P. 460-466.]

[17] Капустин В.И., Марин В.П. // Радиотехника и электроника. 1983. № 6. С. 1159-1162.

[18] Капустин В.И., Ли И.П., Шуманов А.В. // Письма в ЖТФ. 2017. Т. 43. Вып. 12. С. 12-20 [Kapustin V.I., Li I.P., Shumanov A.V. // Tech. Phys. Lett. 2017. Vol. 43. N 10. P. 875-878.] 